\title{
The range of abdominal surgical emergencies in children older than 1 year at the Komfo Anokye Teaching Hospital, Kumasi, Ghana
}

\author{
F. A. Abantanga ${ }^{1,2}$, B. Nimako², M. Amoah ${ }^{2}$ \\ ${ }^{1}$ Department of Surgery, School of Medical Sciences, College of Health Sciences, Kwame Nkrumah University of \\ Science \& Technology, Kumasi, Ghana. 'Directorate of Surgery, Komfo Anokye Teaching Hospital, P.O. Box 1934, \\ Kumasi, Ghana
}

Correspondence to: F. A. Abantanga, Directorate of Surgery, Komfo Anokye Teaching Hospital, P.O. Box 1934, Kumasi, Ghana. Email: frankabantanga@hotmail.com

\begin{abstract}
Background: Acute abdominal conditions are a common reason for emergency admission of children. Little is available in the literature about such conditions in our subregion, especially Ghana.

Objective: The aim of this study was to investigate the range of emergency abdominal surgical conditions amongst children in the subregion, with particular reference to Komfo Anokye Teaching Hospital, Kumasi, Ghana. A prospective survey of all children older than 1 year undergoing an emergency abdominal surgery was carried out.

Methods: Details of all children (except infants) operated for an acute surgical abdominal condition over a 5-year period were entered into a specially designed form, capturing patient characteristics, surgical causes of the emergency, operative procedure, complications, morbidity and mortality rates.

Results: Nine hundred fifty-five children aged $>1$ year but $<15$ years were enrolled in the study. The mean age was $8.8 \pm 3.2$ years. The leading causes of surgical abdominal emergencies were typhoid perforation (TP) of the gastrointestinal tract (GIT), 68\%; acute appendicitis, 16\%; abdominal trauma and intestinal obstruction (including intussusception), $4.7 \%$ each; irreducible external hernias, $2.5 \%$; primary peritonitis, $1.0 \%$; gallbladder disease and gastric perforation, $0.8 \%$ each. Many children died from the TP group; case fatality for TP alone was $12.6 \%$. The overall mortality was $9.7 \%$. Morbidity was influenced by the presence of major peritoneal contamination, continuing peritonitis and surgical site infections (SSIs), which led to long hospital stay.

Conclusions: In our hospital, TP of the GIT, acute appendicitis, intestinal obstruction, irreducible external hernias and primary peritonitis were the most common abdominal emergencies encountered in children after infancy. The high morbidity and mortality in TP is attributable to ignorance, poor sanitation and delay in reporting to hospital for treatment.
\end{abstract}

Keywords: Abdominal emergencies, peritonitis, typhoid perforation

\section{Résume}

Le contexte: Les abdomens aigues sont des motifs fréquents d'admission en urgence des enfants. Peu est disponible dans la littérature à propos de telle conditions dans notre sous région spéciallement au Ghana.

Objectif: Le but de cet article était d'enquêter sur la portée des urgences abdomino-chirurgicales parmis les enfants dans la sous région avec une référence particulière à l'hôpital universitaire de Komfo Anokye, Kumasi, Ghana.

Une étude prospective de tous les enfants de plus de un an qui ont eu une intervention abdominale chirurgicale en urgence a été faite.

Méthodes: Tous les enfants opérés pour un abdomen aigue sur une période de plus de 5 ans ont été enregistrés dans un dossier médical spécial comprenant des renseignements sur le patient, les causes de l'urgence chirurgicale, la procédure operatoire, les complications, la morbidité et la mortalité.

Resultats: Neuf cent cinquante cinq enfants de plus de un an mais moins de 15 ans ont fait l'objet de cette étude. L'âge moyen était de 8.8 plus ou moins 3.2 ans. La cause majeure des urgences abdomino-chirurgicales étaient: 
la perforation typhique (PT) de l'appareil digestif (AD) -68\%; l'appendicite aigue-16\%; le traumatisme abdominal et l'occlusion intestinale- $4.7 \%$ chacun; les hernies externes irreductible- $2.5 \%$; les péritonites primaires-1\%; les maladies de la vésicule biliaire et la perforation gstrique- $0.8 \%$ chacun. La morbidité était influencée par la présence de contamination péritoneale majeure, de péritonite pèrsistente, et d'infection de site opératoire(ISO) qui ont conduit à une hôspitalisation prolongée. Beaucoup d'enfants étaient morts dans le groupe de PT; le taux de mortalité particulier au PT était de 12.6\%. La mortalité générale était de $9.7 \%$.

Conclusions: La perforation typhique de I 'appareil digestif, l'appendicite aigue, l'occlusion intestinale, les hernies externes irréductible, et les péritonites primaires sont les plus fréquentes urgences abdominales chez les enfants après la petite enfance dans notre hôpital.

La morbidité et la mortalité élevée dans les perforations typhiques est attribuable à l'ignorance, aux pauvres conditions sanitaires et le retard de présentation à l'hôpital pour traitement.

Mots cles: Perforation typhique, urgence abdominale, péritonite

DOI: $10.4103 / 1596-3519.59578$

\section{Introduction}

Surgical abdominal emergencies in children are the most challenging and difficult problems for the pediatric surgeon. There are difficulties inherent in the examination of children, ${ }^{[1]}$ especially those with abdominal pain and who, for that matter, are uncooperative; and also of children with an unclear history. Another major problem is that most children admitted with acute abdominal pain in our environment come from rural communities, and presenting late for treatment is the rule and not the exception. Their parents usually tend to use herbal preparations and/or buy over-the-counter drugs for their children, hoping that the pain will disappear; and when it does not, they visit various peripheral primary health care facilities, where they are either mismanaged ${ }^{[2]}$ or detained for a number of days before being referred to our center, usually late and in a very bad state. Many from the rural areas die from untreated abdominal emergencies ${ }^{[3]}$ as a result of lack of health education, poverty, poor hygiene and sanitation and poor living conditions and facilities. ${ }^{[4]}$

Most children with abdominal pain are admitted to Komfo Anokye Teaching Hospital from all the communities in and around it. There are no data in the literature about the surgical conditions that can lead to abdominal pain in children from areas under the municipality of Kumasi. We therefore set out primarily to define the spectrum of acute abdominal surgical conditions in children after infancy and determine the outcome after treatment.

\section{Materials and Methods}

From January 2001 to December 2005, all consecutive children aged $>1$ year but $<15$ years undergoing laparotomy for an acute intra-abdominal condition were prospectively enrolled in the study.
Patient characteristics, diagnoses, postoperative complications, morbidity and mortality rate were all evaluated. Komfo Anokye Teaching Hospital serves the whole of Ashanti Region of Ghana, with a population of about 4.7 million, of which $41.9 \%$ are children below the age of 15 years. Referrals are also received from other parts of the country.

Descriptive statistics were produced using SPSS version 10.0 for windows where appropriate. A $P$ value $<0.05$ was considered statistically significant.

\section{Results}

Nine hundred fifty-five (955) children were included in the study. There were 568 boys and 387 girls, giving a male-to-female ratio of 1.5:1. Figure 1 shows the age groups and sex distribution of the children under study. The overall mean age of the children was $8.8 \pm 3.2$ years (boys, $8.9 \pm 3.1$ years; and girls, $8.7 \pm 3.2$ years; $P=0.26)$ with an age range of $1.2-14.5$ years. The most common abdominal emergency was typhoid perforation (TP) of the gastrointestinal tract (GIT), which accounted for over $68.0 \%$ of the children, with a male-to-female ratio of 1.3:1.0; followed by acute appendicitis, about $16.0 \%$, with a male-to-female ratio of 2.0:1.0; and various types of abdominal traumas, intestinal obstructions (excluding intussusception) and irreducible external hernias - 5.0\%, 3.0\% and $3.0 \%$, respectively. Other emergencies which required a laparotomy included intussusception in $2.0 \%$ of the children; primary peritonitis in over $1.0 \%$; and gallbladder diseases (acute gangrenous cholecystitis, acute perforated cholecystitis and empyema of the gallbladder) and gastric perforation each in $0.8 \%$ of the children. Complications of ovarian cysts/masses were seen in $0.5 \%$ of the children; and Meckel's diverticulitis, anastomotic breakdown (referred from district hospitals) and perforated lymphoma (nonHodgkin's) of the intestine were each seen in $0.2 \%$ of the children [Table 1]. 


\begin{tabular}{lccr}
\hline \multicolumn{2}{l}{ Table 1: Postoperative diagnosis and sex of children $(n=\mathbf{9 5 5})$} & Sex & Total (\%) \\
\cline { 2 - 4 } Diagnosis & Female (\%) & $370(56.9)$ & $650(68.1)$ \\
& $280(43.1)$ & $100(66.2)$ & $151(15.8)$ \\
\hline Typhoid perforation & $51(33.8)$ & $31(68.9)$ & $45(4.7)$ \\
Acute appendicitis & $14(31.1)$ & $18(64.3)$ & $28(2.9)$ \\
Abdominal trauma & $10(35.7)$ & $20(83.3)$ & $24(2.5)$ \\
Intestinal obstruction & $4(16.7)$ & $13(76.5)$ & $17(1.8)$ \\
Irreducible external hernia & $4(23.5)$ & $0(0.0)$ & $10(1.0)$ \\
Intussusception & $10(100.0)$ & $5(62.5)$ & $8(0.8)$ \\
Primary peritonitis & $3(37.5)$ & $3(37.5)$ & $8(0.8)$ \\
Gallbladder disease & $5(62.5)$ & - & $5(0.5)$ \\
Gastric perforations & $5(100.0)$ & $1(50.0)$ & $2(0.2)$ \\
Ovarian cyst & $1(50.0)$ & $2(100.0)$ & $2(0.2)$ \\
Breakdown of anastomosis & - & $1(50.0)$ & $2(0.2)$ \\
Acute Meckel's Diverticulitis & $1(50.0)$ & $1(100.0)$ & $1(0.1)$ \\
Lymphoma of small intestine & & $1(100.0)$ & $1(0.1)$ \\
with perforation & - & $1(100.0)$ & $1(0.1)$ \\
Burst intra-abdominal abscess & - & $567(59.4)$ & $955(100.0)$ \\
Enterogenic cyst with peritonitis & - & & \\
Ruptured liver abscess & $388(40.6)$ & & \\
Total & & & \\
\hline
\end{tabular}

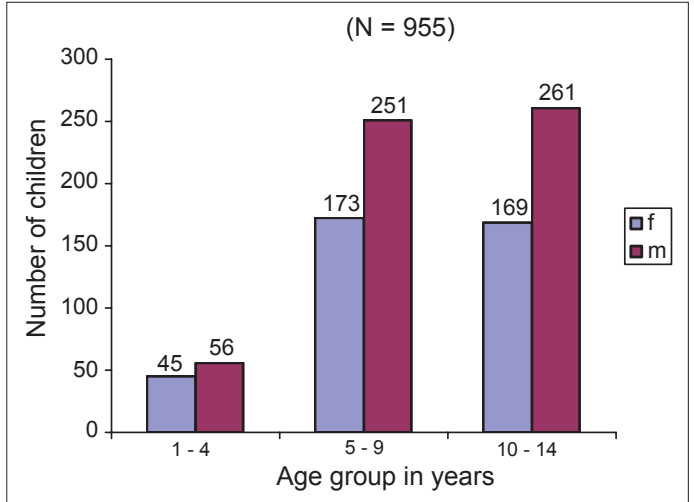

Figure 1: Distribution of children with surgical abdominal emergencies from 2001 to 2005 by age group and sex $(n=955)$

Of the 650 children who were suspected of having TP, 36 had peritonitis only without perforation, out of whom 3 died after surgery; 614 had perforations of the GIT (ileum, cecum, colon, rectum and stomach). Of the group with perforations of the GIT, 9 died postoperatively.

Simple acute appendicitis was observed in 20 (13.2\%) children; and complicated acute appendicitis, in 131 (86.8\%). One child died after appendicectomy for a complicated appendicitis.

Abdominal trauma was diagnosed in 45 children, of whom 32 were blunt and 13 were penetrating. In the group with blunt abdominal trauma, the spleen was the major cause of hemoperitoneum, requiring a laparotomy in 22 children. Those with penetrating abdominal injury had obtained such injuries from accidental gunshot wounds (3); falls from heights with objects penetrating them through the perineum into the abdominal cavity (2); deep

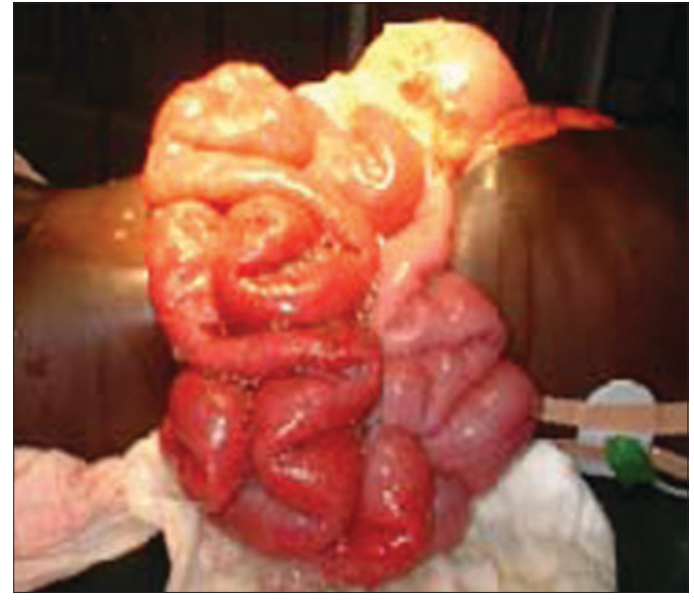

Figure 2: An 8-year-old boy who fell from an orange tree in an attempt to harvest oranges with a sickle. The sickle cut him from the chest wall to the abdominal wall. The right lung was collapsed and all the intestines protruded out of the wound as seen here

laceration involving the chest and the abdominal walls caused by a fall from an orange tree against a sickle used in harvesting oranges (1) [Figure 2]; and road traffic injuries (7). Two children from this group died.

The intestinal obstruction group (excluding intussusception) included postoperative obstruction secondary to adhesions (22); obstruction due to intramural tumors (2); volvulus of the small intestine (1); and obstruction as a result of a huge intra-abdominal abscess (1). Mortality in this group was $7.1 \%$. Intussusception was diagnosed in 17 children. The mean age for this group was $5.4 \pm 3.8$ years (range, $1.2-13.0$ years). There were 5 cases of ileo-ileal intussusception, 3 cases of ileo-colic, 6 of caeco-colic, 2 of colo-colic and 1 case of ileo-sigmoid intussusception with prolapse through the anal orifice. Over a third (35.3\%) of 
these children had bowel resection done because of gangrenous bowel. One child from this group died.

Twenty-four children were operated for various irreducible external hernias: 10 strangulated inguinal (including two Richter's hernias), 10 obstructed inguinal and 4 umbilical hernias (strangulated, 2; obstructed, 2).

Primary peritonitis was the cause of acute abdomen in 10 girls in whom the diagnosis was established intraoperatively in this study. We did not culture any microorganisms from the peritoneal fluid.

In all, 8 children had a gallbladder disease, acute enough to require emergency laparotomy. Acute gangrenous cholecystitis was diagnosed in 3 children; perforated, in 3; and empyema of the gallbladder, in 2 children. Two children from this group died.

Eight children had isolated gastric perforations for which the exact cause could not be determined. From the history, it was established that 2 children were regularly given nonsteroidal anti-inflammatory drugs (NSAIDs) by the parents for chronic abdominal pains, and the remaining 6 children used herbal preparations very regularly. Two (25.0\%) children from this group died after surgery.

During laparotomies for the various diseases in the group under review, 77 (8.1\%) children had bowel resection done with re-establishment of bowel continuity. Most of the bowel resections occurred in the TP (63.6\%), the intussusception (7.8\%), the intestinal obstruction (6.5\%) and the strangulated external hernias (5.2\%) groups. Of those who had bowel resection performed, 17 (22.1\%) died from various postoperative complications.

Surgical site infection (SSI) occurred in 227 children postoperatively: Superficial SSI-54 (23.8\%); deep SSI-56 (24.7\%); incomplete wound dehiscence-88 (38.8\%); and complete wound dehiscence (burst abdomen)-29(12.8\%) children. These SSIs together with other complications such as bronchopneumonia, severe anemia, septicemia and malnutrition greatly affected morbidity (especially, length of stay [LOS] in hospital) and outcome. LOS in hospital ranged from 1 day to 77 days. Mean LOS in hospital was $14.4 \pm 9.9$ days (median, 12 days; mode, 10 days). Six children stayed in hospital for only 1 day each; 5 of them died on the first postoperative day, and 1 child was discharged the same day after surgery for an obstructed inguinal hernia. A child with typhoid ileal perforation stayed in hospital for 77 days as a result of deep SSI with a resultant enterocutaneous fistula. She was treated conservatively due to her poor general condition.

Overall mortality was $9.7 \%$ (54 girls and 39 boys); the odds ratio for a female dying as compared to a male being 2.2 (95\% confidence interval $=1.4$ to 3.4). Most of the deaths occurred in the TP group - 82 children, representing $88.2 \%$ of all deaths in this study [Table 2].

\section{Discussion}

The most common abdominal surgical emergency encountered in children aged $>1$ year but $<15$ years in our environment is TP of GIT. The occurrence of so many cases of TP is mainly because of the unhygienic conditions prevailing in our environment, ignorance, increased virulence of the bacterium and also increased susceptibility due to malnutrition and poor immunity. ${ }^{[5]}$ The prognosis of typhoid ileal perforation is still poor despite several years of treating it in our societies, with mortality rates ranging from $10 \%$ to $25 \%$ in children. ${ }^{[5,6]}$ In this study, case fatality for TP was $12.5 \%$ and this was as a result of overwhelming sepsis, postoperative continuing peritonitis, wound infection and wound dehiscence. ${ }^{[7]}$ It was noted that mortality among children with multiple perforations (4 or more) stood at $28 \%$. Typhoid fever leading to typhoid ileal perforation has a devastating impact on the economies of developing countries ${ }^{[8]}$ and is a drain on the scarce resources of hospitals treating such

\begin{tabular}{lcc}
\hline \multicolumn{2}{l}{ Table 2: Fatality rates among children with abdominal surgical emergencies $(\boldsymbol{n}=\mathbf{9 5 5})$} & \\
\hline Abdominal surgical emergency & Total number of children & Fatality rate (\%) \\
\hline Typhoid perforation of the GIT & 650 & $82(12.6)$ \\
Abdominal trauma & 45 & $2(4.4)$ \\
Intestinal obstruction & 28 & $2(7.1)$ \\
Gallbladder disease & 8 & $2(25.0)$ \\
Gastric perforation & 8 & $2(25.0)$ \\
Acute appendicitis & 151 & $1(0.7)$ \\
Intussusception & 17 & $1(5.9)$ \\
Perforated lymphoma & 2 & $1(50.0)$ \\
of the small bowel & & \\
Miscellaneous & 46 & - \\
Total & 955 & $93(9.7)$ \\
\hline
\end{tabular}


patients. Vigorously tackling poverty, poor hygiene and poor sanitation by governments in the subregion will eliminate the disease or diminish its effects. We do agree with Archampong ${ }^{[9]}$ that tropical diseases that affect the small bowel leading to perforations are predominantly preventable; and so their continued prevalence among causes of acute abdomen indicates an unrealistic allocation of priorities in the mass control of endemic diseases.

Page $\mid 240$

Acute appendicitis was the next most common surgical emergency in the study, accounting for about $16 \%$ of all cases. It is noted to be a common cause of abdominal pain in children; ${ }^{[10]}$ diagnosis can be difficult ${ }^{[11,12]}$ and the condition if untreated has the potential for evoking severe complications such as perforations, intra-abdominal sepsis and wound infection. Evaluation of children with abdominal pain is often difficult, and as such, perforation rates for acute appendicitis are higher than in the adult population; ${ }^{[1]}$ also, because of the less developed nature of the omentum, perforations in children very often lead to generalized peritonitis, the omentum being unable to wall off or localize the spillage from the perforations. ${ }^{[1]}$ In the present series, complicated acute appendicitis occurred in over $86.8 \%$ of the group; out of this number, perforations were registered in $68(49.0 \%)$ children. In an earlier study of acute appendicitis in children in this same hospital, it was noted that a vast majority of the children had complicated appendicitis with over $38 \%$ having perforations. ${ }^{[13]}$ This obviously indicates that complication rate of acute appendicitis is increasing in children in our environment, mainly due to ignorance on the part of parents about the disease, self-medication and delay in reporting to hospital. According to reports from the same hospital ${ }^{[14]}$ and also from Nigeria, ${ }^{[15]}$ in adults the most common abdominal emergency was acute appendicitis, accounting for over $22 \%$ and $15 \%$, respectively, of all acute surgical admissions for abdominal pain; this was followed by typhoid ileal perforation ${ }^{[14]}$ - a reversal of the situation seen in children in this study. This may be due to the fact that acute appendicitis is less common in young children, especially children under the age of 5 years. ${ }^{[16,17]}$ In a study similar to ours from Nigeria, ${ }^{[16]}$ appendicitis ranked third after intestinal obstruction and typhoid perforation as one of the most common surgical emergency in children, with two thirds of the children in that study having complicated appendicitis; in our series, about $87 \%$ had complicated appendicitis.

Abdominal trauma and intestinal obstruction (including intussusception) were the next most frequent causes of emergency abdominal surgeries in this series. Blunt abdominal trauma was a major reason for laparotomies performed in over $71 \%$ of our children with abdominal injury. The organ most often injured was the spleen, similar to reports from Nigeria. ${ }^{[18]}$ As a result, many spleens were removed for various grades of splenic injuries. Since 2003, we have reviewed our stand on exploratory laparotomies for all cases of hemoperitoneum involving the spleen, taking into consideration the immunologic role of the spleen and the improvement of the diagnostic tools for blunt abdominal trauma in our hospital, and have evolved nonoperative methods of management of most splenic injuries, as accepted in many centers worldwide. ${ }^{[19,20]}$ The penetrating abdominal injuries mainly involved accidental gunshot wounds, falls from heights [Figure 2] and road traffic injuries.

Intestinal obstruction (including intussusception) accounted for $4.5 \%$ of the cases. In many series, intestinal obstruction is the most common cause of emergency abdominal surgery in children of all ages. ${ }^{[16]}$ Intussusception was not the leading cause of intestinal obstruction in children in the present study. This is understandable, because children aged 1 year and below were not included in the analysis. Intussusception ranked second to adhesive intestinal obstruction in the present series. A majority of the intussusceptions were either ceco-colic or ileoileal, as opposed to the findings in the literature, which indicated that the most predominant intussusception was ileo-colic ${ }^{[21]}$ in infants. In the present study, it was observed that there were no pathological lead points (masses) present in the intussusceptions as is generally accepted in the literature on intussusceptions in children aged 2 years and above. ${ }^{[22,23]}$ As many as $35.3 \%$ of the children with intussusception had bowel resection done. Children with intussusception in our series reported more than 24 hours late to the hospital after the appearance of the first symptoms. They were, most often, seen and treated in other health facilities for dysentery or bloody diarrhea and were only referred when a mass was palpated in the abdomen or when the condition did not improve. There was one unusual intussusception in the series, viz., ileo-sigmoid intussusception - so far, the only one reported in children in the literature. ${ }^{[24]}$ A similar intussusception was recently reported in adults. ${ }^{[25]}$

Irreducible external hernias as a cause of emergency abdominal surgical admissions were found in $2.5 \%$ of our cases. These emergencies are a potential cause of worry for surgeons, in the sense that inguinal hernias are commonly obstructed at the external inguinal ring with a high possibility of strangulation and bowel gangrene ${ }^{[2]}$ if steps are not taken early to reduce such hernias. We usually first attempt to manually reduce all incarcerated hernias in children (except where 
there is obvious peritonitis) after giving a sedative and an analgesic, and only those hernias that cannot be reduced manually are operated. This explains why the number of irreducible external hernias in our series is small. Those patients in whom the hernias are successfully reduced are kept in the hospital for at least 48 hours for observation and scheduled for herniotomy on the next available elective surgery day. All hernias that were operated on after manual reduction had normal intestines. A fifth of the children with strangulated inguinal hernias and all the children with strangulated umbilical hernias had resection done because of gangrenous bowel; in other words, $16.7 \%$ of children in the series who had irreducible external hernias required intestinal resection because of nonviable bowel.

Primary peritonitis is relatively uncommon and tends to affect girls more than boys. Failure to clinically recognize the condition may result in unnecessary surgery and increased morbidity. ${ }^{[26]}$ It is an acute intra-peritoneal inflammatory process for which no intra-abdominal etiologic focus is found ${ }^{[27]}$ except for thick creamy purulent exudate. It was difficult excluding acute appendicitis in these girls since the disease mimics it, ${ }^{[28]}$ hence the decision to operate.

The children who had gallbladder diseases tended to have either cholecystitis (perforated or gangrenous) or empyema. We suspected them to be due to enteric fever but were unable to confirm this through culture of the contents of the gallbladders removed during surgery.

In the 8 children with gastric perforations, we were able to elicit through detailed history taken that they routinely used NSAIDs, usually self-administered or given by parents for abdominal pain; others abused herbal concoctions regularly — also mostly supplied by parents who were themselves habitual users. In a study in adults from the same institution, the authors ${ }^{[29]}$ observed that most gastric and duodenal perforations were associated with the intake of NSAIDs and consistent ingestion of herbal concoctions. We think this may also be true for the children we treated in this study.

In 5 girls, a diagnosis of torsion of ovarian masses/cysts was made as a differential to acute appendicitis. The signs and symptoms experienced by all these girls tended to mimic acute appendicitis, which has also been noted by other workers. ${ }^{[30]}$ They all had emergency laparotomy done with excision of the cysts and teratomas.

The less frequent causes of surgical abdominal emergencies in children included a perforated enterogenic cyst, perforated non-Hodgkin's lymphoma, Meckel's diverticulitis, ${ }^{[2]}$ ruptured liver abscess and a burst intra-abdominal abscess leaking through an umbilical defect. The 2 cases of anastomotic breakdown were referred from two district hospitals; and in both cases, the reason for the first laparotomy was not stated. Both patients survived re-laparotomy, resection and re-anastomosis of bowel.

As already stated above, morbidity in the series was a major problem and was mainly due to the poor conditions of the children - malnutrition, anemia and compromised immunity. ${ }^{[5]}$ Morbidity was especially high in children with TP, who developed so many complications and stayed in the hospital for longer periods. Again, postoperative complications in the form of SSIs were noted mostly in the TP group. The worse complications in this series included enterocutaneous fistulas and complete wound dehiscence (burst abdomen), these two being associated with high morbidity and mortality. ${ }^{[31]}$ More deaths were recorded in the TP group when compared to the groups with other disease entities. Mortality in the series was 9.7\%, and this was mainly due to deaths in the TP group.

\section{Conclusion}

TP of the GIT; acute appendicitis; abdominal trauma; intestinal obstruction, including intussusception; and irreducible external hernias are the most common disease entities that are the causes of acute abdominal pain in children in our environment. With proper planning, education on good hygiene and sanitation and mass control of communicable and noncommunicable childhood diseases, many of these conditions can be controlled.

\section{Acknowledgment}

We are grateful to Dr. Ayayi Hillah for translating the abstract of this paper into French.

\section{References}

1. McCollough M, Sharieff GQ. Abdominal pain in children. Pediatr Clin N Am 2006;53:107-37.

2. Hussain Z, Sheikh KA, Lone R, Arif S, Rasool A, Mudassir S, et al. Small bowel obstruction in children: A surgical challenge. JK Pract 2006;13:186-9.

3. McConkey S]. Case series of acute abdominal surgery in rural Sierra Leone. World ] Surg 2002;26:509-13.

4. Wani MM, Khan MA, Wani MM, Durrani AM, Singh B, Shafi M. Analysis of acute abdomen admission in the surgical emergency room of a developing third world country. Int ] Surg 2007;11:2.

5. Uba AF, Chirdan LB, Ituen AM. Typhoid intestinal perforation in children: A continuing scourge in a developing country. Pediatr Surg Int 2007;23:33-9.

6. Rahman GA, Abubakar AM, Johnson AW, Adeniran JO. Typhoid ileal perforation in Nigerian children: An analysis of 106 operative cases. Pediatr Surg Int 2001;17:628-30. 
7. Adesunkanmi ARK, Ajao OG. The prognostic factors in typhoid ileal perforation: A prospective study of 50 patients. J R Coll Surg Edinb 1997;42:395-9.

8. Hosoglu S, Aldemir M, Akalin S, Geyik MF, Tacyildiz IH, Loeb M. Risk factors for enteric perforation in patients with typhoid fever. Am J Epidemiol 2004;160:46-50.

9. Archampong EQ. Tropical diseases of the small bowel. World ] Surg 1985;9:887-96.

10. Rothrock SG, Pagane J. Acute appendicitis in children: Emergency department diagnosis and management. Ann Emerg Med 2000;36:39-51.

Page $\mid 242$

11. Kirby CP, Sparnon AL. Active observation of children with possible appendicitis does not increase morbidity. ANZ J Surg 2001;71:412-3.

12. Yang HR, Wang YC, Chung PK, Chen WK, Jeng LB, Chen RJ. Laboratory tests in patients with acute appendicitis. ANZ ] Surg 2006;76:71-4.

13. Abantanga FA. Acute appendicitis in children in Kumasi, Ghana: Macroscopic findings at laparotomy. Afr ] Paediatr Surg 2004;1:6-10.

14. Ohene-Yeboah M. Acute surgical admissions for abdominal pain in adults in Kumasi, Ghana. ANZ ] Surg 2006;76:898-903.

15. Chianakwana GU, Ihegihu CC, Okafor PI, Anyanwu SN, Mbonu OO. Adult surgical emergencies in a developing country: The experience of Nnamdi Azikiwe Teaching Hospital, Nnewi, Anambra State, Nigeria. World ] Surg 2005;29:804-8

16. Abubakari AM, Ofoegbu CP. Factors affecting outcome of emergency paediatric abdominal surgery. Niger ] Surg Res 2003;5:85-91.

17. Bratton SL, Haberkern CM, Waldhausen HT. Acute appendicitis risks of complications: Age and Medicaid Insurance. Pediatrics 2000;106:75-8.

18. Chirdan LB, Uba AF, Yiltok S], Ramyil VM. Paediatric blunt abdominal trauma: Challenges of management in a developing country. Eur ] Pediatr Surg 2007;17:90-5.

19. Kumar MM, Venkataramanappa M, Venkataratnam I, Kumar NV, Babji K. Prospective evaluation of blunt abdominal trauma by computed tomography. Indian ] Radiol Imaging 2005;15:167-73.

20. Al-Shanafey S, Giacomantonio M, Jackson R. Splenic injuries in children: Correlation between imaging and clinical management. Pediatr Surg Int 2001;17:365-8.

21. Daneman A. Intussusception: An approach to management. In: Hodler ], Von Schulthess GK, Zollikofer Ch L, editor. Diseases of the abdomen and pelvis. Springer Milan; 2006. p. 218-23.

22. Simanovsky N, Hiller N, Koplewitz BZ, Eliahou R, Udassin R. Is non-operative intussusception reduction effective in older children? Ten-year experience in a university affiliated medical center. Pediatr Surg Int 2007;23:261-4.

23. Ratan SK, Rattan KN, Pandey RM, Sehgal T, Kumar A, Ratan ]. Surgically treated gastro-intestinal obstruction in children: Causes and implications. Indian ] Gastroenterol 2006;25:320-1.

24. Abantanga FA. Ileal invagination of the sigmoid colon producing a sigmoidorectal intussusception combined with rectal prolapse in a 3-year-old boy. Pediatr Surg Int 2005;21:400-2.

25. David AW, Stephen E, Pradhan NR, Nayek S, Perakath B. Adult idiopathic ileosigmoid intussusception prolapsing per rectum. Indian ] Gastroenterol 2007;26:39-40.

26. Zhou H, Cheng W. Primary peritonitis in children. Ann Coll Surg Hong Kong 2000;4:53-6.

27. Mayer MP, Schweizer P. Primary peritonitis in a child caused by Haemophilus parainfluenzae. Pediatr Surg Int 2002;18:728-9.

28. Dann PH, Amodio JB, Rivera R, Fefferman NR. Priamary bacterial peritonitis in otherwise healthy children: Imaging findings. Pediatr Radiol 2005;35:198-201.

29. Ohene-Yeboah M, Togbe B. Perforated gastric and duodenal ulcers in an urban African population. West Afr ] Med 2006;25:205-11.

30. Piipo S, Mustaniemi L, Lenko H, Aine R, Mäenpää ]. Surgery for ovarian masses during childhood and adolescence: A report of 79 cases. J Pediatr Adolesc Gynecol 1999;12:223-7.

31. çiğdem MK, Onen A, Otçu S, Duran H. Postoperative abdominal evisceration in children: Possible risk factors. Pediatr Surg Int 2006;22:677-80.

Source of Support: Nil, Conflict of Interest: None declared. 